\title{
A Novel Approach for Cannulation to the Ampulla Within the Diverticulum: Double-Catheter Method
}

A 75-year old woman presented with cholangitis caused by a common bile duct stone. ERCP was performed using a sideviewing duodenoscope (TJF200, Olympus, Tokyo, Japan) equipped with a 12 Fr working channel. After successful duodenal intubation, we found that a large diverticulum overrode the ampulla and eventually overwhelmed it (Figure 1). The ampulla could be brought outside only by everting the rim of the diverticulum with a $5 \mathrm{Fr}$ standard-tipped Teflon ERCP catheter (Medizin-Technische-Werkstätte, Germany). However, it returned to its original position as soon as the catheter was moved to cannulate the papillary orifice. Many attempts using suction, position change or abdominal compression were unable to maintain the everted position of the ampulla. We therefore decided to use an addi- tional catheter to keep the ampulla outside the diverticulum. When we pushed the duodenal fold downward and laterally with the first catheter, the ampulla was everted from the diverticulum and the hidden papilla brought into view. Once the papilla was visible, the second catheter, which was identical to the first, was advanced alongside it and inserted into the papillary orifice without difficulty (Figure 2); a successful cholangiogram was obtained. After the insertion of a guide wire through the second catheter, sphincterotomy and stone removal were also performed successfully.

An ampulla within the diverticulum is not so rare, especially in elderly patients with duct stones [1], but may pose a problem in identifying the papilla and properly orient- ing this structure for cannulation [2]. Batra et al. [3] reported a method of cannulation of the ampulla within the diverticulum, which is similar to ours but we use a guide wire as an additional accessory. Unlike a Teflon catheter, however, the guide wire is not flexible enough to be well controlled by the elevator. The limiting factor in our method is the diameter of the endoscope. Because the working channel has to contain two catheters simultaneously, an endoscope with a working channel of at least 10 Fr must be employed.

H. J. Kim, Y. S. Kim, S. J. Myung,

D. W. Seo, S. K. Lee, M. H. Kim, Y. I. Min

Dept. of Internal Medicine,

Asan Medical Center,

University of Ulsan College of Medicine, Seoul, Korea 


\section{S104 Unusual Cases and Technical Notes}

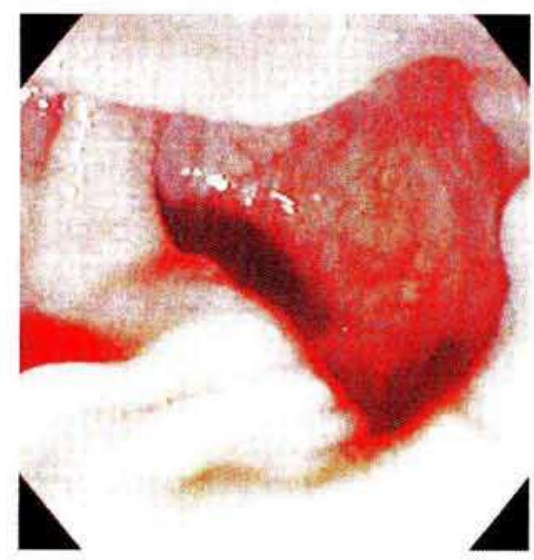

Figure 1 The ampulla within the diverticulum

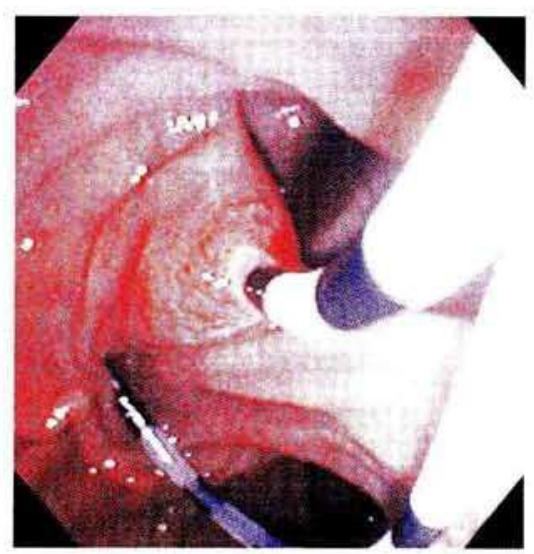

Figure 2 After anchoring the ampulla outside the diverticulum with the first catheter, the second catheter was advanced by the side of the first one and inserted into the papillary orifice without difficulty

\section{References}

1. Kennedy RH, Thompson MH. Are duodenal diverticula associated with choledocholithiasis? Gut 1988; 29: 1003-6

2. Cotton PB, Williams CB. Practical gastrointestinal endoscopy. In: Endoscopic retrograde cholangiopancreatography. Blackwell, 3rd ed. Oxford, 1990: $85-117$

3. Batra SC, Trowers E Jr, Dayemo K, Singh HP. Novel approach to ampullary cannulation. Gastrointest Endosc 1996; 44: $360-1$

Corresponding Author

M.-H. Kim, M.D.

Dept. of Internal Medicine

Asan medical Center

388-1 Poongnapdong

Songpagu, Seoul 138-040, Korea

Fax: +82 (2) 476-0824

E-mail: sjmyung@www.amc.seoul.kr 